\title{
PENGARUH DISIPLIN KERJA TERHADAP KINERJA KARYAWAN PADA BANK OCBC NISP CABANG CIBADAK-SUKABUMI (Survey Pada Karyawan Bank OCBC NISP Cabang Cibadak)
}

\author{
Yunia Lestari ${ }^{1}$, Faizal Mulia ${ }^{2}$, Nor Norisanti ${ }^{3}$ \\ 1,2,3Fakultas Ilmu Administrasi dan Humaniora, Universitas Muhammadiyah Sukabumi \\ Email: yunialestari@ummi.ac.id ${ }^{1}$, faizal_88@ummi.ac.id, nornorisanti@ummi.ac.id ${ }^{3}$
}

\section{INTISARI}

Penelitian ini bertujuan untuk mengetahui seberapa besar kontribusi kedisiplinan kerja dalam meningkatkan kinerja karyawan Bank OCBC NISP Cabang Cibadak Sukabumi, serta seberapa besar melihat pengaruh disiplin kerja terhadap kinerja karyawan baik secara simultan ataupun parsial. metode yang telah dipergunakan dalam penelitian ini adalah metode penelitian kuantitatif dengan analisis regresi linier sederhana sebagai teknik analisa data, dengan jumlah responden sejumlah 32 orang yaitu dengan menggunakan survey melalui kuesioner kepada karyawan Bank OCBC NISP Cabang Cibadak . hasil penelitian ini dapat menunjukan disiplin kerja sangat berpengaruh positif dan signifikan kepada kinerja karyawan. Total pengaruhnya sebesar $65,3 \%$ dan sisanya sebesar 34,7\% .dipengaruhi oleh variabel yang tidak di teliti dalam penelitian ini .

Kata kunci: Disiplin Kerja, Kinerja Karyawan

\section{ABSTRACT}

This study aims to determine how much the contribution of work discipline in improving the performance of employees of Bank OCBC NISP Cibadak Sukabumi Branch, as well as to see how much influence the work discipline has on employee performance either simultaneously or partially. The method used in this study is a quantitative research method with simple linear regression analysis as a data analysis technique, with 32 respondents consisting of a survey through a questionnaire to Bank OCBC NISP Cibadak Branch employees. the results of this study can show that working discipline has a positive and significant effect on employee performance. The total effect is $65.3 \%$ while the remaining $34.7 \%$ is influenced by variables not examined in this study.

Keywords: Work Discipline, Employee Performance

\section{PENDAHULUAN}

Dalam sebuah perusahaan Sumber Daya Manusia adalah suatu kesatuan yang tidak bisa untuk diurai atau dipisahkan. Dengan ada keduanya sebuah perusahaan akan berjalan dengan sangat lancar sesuai dengan apa yang telah diharapkan oleh perusahaan yang didalamnya terdapat individu yang memiliki tujuan dan impian yang sama, yang ingin menjadikan perusahaan tersebut mengalami peningkatan dan berkembang dari tahun ke tahunnya. Individu atau karyawan merupakan factor utama yang dibutuhkan oleh perusahaan atas aktivitas dan kegiatan yang ada didalam sebuah perusahaan, karena peranan tersebut dengan itu perusahaan harus bisa memberikan perhatian yang lebih dan khusus bagi karyawan. Selain itu hal yang sangat berpengaruh dalam sumber daya manusia itu adalah sikap disiplin. Kedisiplinan dalam bekerja adalah hal yang sangat berpengaruh besar dalam kegiatan yang dilakukan karyawan didalm perusahaan dan sangat besar manfaatnya bagi perusahaan maupun karyawan itu sendiri.

Dengan adanya kedisiplinan dalam bekerja maka kelancaran pelaksanaan tugas sekaligus tat tertib yang ada di perusahaan akan berjalan dengan lancar. Dengan itu perusahaan akan mencapai target dengan optimal sesuai dengan harapan perusahaan. Sedangkan bagi karyawan itu sendiri akan memperoleh suasan kerja dan lingkungan yang nyaman serta menyenangkan untuk melakuikan kegiatan didalam perusahaan. 
Dengan demikian semuan karyawan dapat melaksanakan pekerjaan nya dengan penuh kesadaran dan menjadikan tempat kerja sebagai tempat yang nyaman serta semangat dalam bekerja semakin meningkat dan dapat melakukan pekerjaan dengan maksimal serta dapat mengembangkan tenaga seoptimal mungkin untuk mencapai tujuan dan target yang telah di tetapkan perusahaan. Dengan begitu apabila lingkungan kerja semuanya disiplin maka semua individu yang ada disebuah perusahaan akan ikut disiplin dalam bekerja. Akan tetapi apabila didalam sebuah perrusahaan tidak diterapkan kedisiplinan maka individu yang berada dalam lingkungan tersebut akan ikut serta tidak disiplin, karena lingkungan kerja akan menjadi panutan dan patokan bagi karyawan.

Bank OCBC NISP pada cabang Cibadak adalah suatu Lembaga keuangan terbesar yang didirikan pada tahun 1967. Bank OCBC NISP menjadi bank komersial yang menyadiakan berbagai layanan perbankan. Bank OCBC NISP juga memberikan partisipasi pada programprogram tabungan pemerintah dan menyalurkan kredit yang disubsidi pemerintah.

Dengan latar belakang dalam masalah tersebut serta dukungan landasan teoritis yang dikemukakan, dengan itu penulis tertarik utnuk mengambil judul "Pengaruh Disiplin Kerja Terhadap Kinerja Karyawan (Survey pada Bank OCBC NISP cabang Cibadak)”

\section{TINJAUAN PUSTAKA DAN PENGEMBANGAN HIPOTESIS Disiplin Kerja}

Dalam hal ini Hasibuan menjabarkan tentang Disiplin Kerja sebagai berikut, menurut Hasibuan (2006:237) yang berpendapat bahwa kedisiplinan adalah bentuk suatu kesadaran dan ketersediaan individu untuk mentaati sebuah peraturan dan norma-norma yang berlaku didalam perusahaan. Oleh karena itu bisa dikatakan disiplin apabila karyawan bersedia melakukan semua tugas dan tanggung jawabnya penuh dengan kesadaran. Karena kedisiplinan adalah sebagai kunci keberhasilan perusahaan harus ditegakkan dalam sebuah organisasi perusahan untuk mencapai tujuan dan harapan Bersama.

Menurut pendapat Harlie (2010) indikator-indikator disiplin kerja di adalah sebagai berikut: (1) selalu datang dengan tepat waktu (2) selalu mengutamakan presentase kehadiran (3) selalu mengikuti dan mentaati ketentuan darijam kerja (4) selalu menggunakan jam kerja dengan efisien dan seefektif mungkin (5) memiliki kecakapan dan keterampilan kerja pada bidang tugasnya (6) mempunyai semangat kerja yang sangat tinggi (7) memiliki prilaku yang baik (8) selalu memiliki kreatifitas dan inovatif dalam melakukan pekerjaan..

Disiplin kerja merupakan fungsi operatif manajemen sumber daya manusia yang sangat penting, karena semakin baiknya disiplin kerja seorang karyawan maka akan semakin tinggi prestasi juga pekerjaan yang dapat dicapainya, akan tetapi apabila tidak adanya penerapan disiplin kerja yang baik akan menjadi sulit bagi sebuah perusahaan untuk mendapatkan hasil yang optimal, (Hasibuan, 2006:193). Disiplin kerja sendiri tidak hanya bermanfaat untuk mencapai tujuan perusahaan saja, akan tetapi bagi karyawan juga karena disiplin kerja dapat meningkatkan gairah bekerja dan semangat kerja karyawan.

Menurut Sinambela (2016:332) disiplin juga bermanfaat untuk mendidik pegawai dalam mematuhi dan mentaati peraturan, prosedur, serta kebijakan yang ada sehingga menghasilkan kinerja yang baik. Untuk memelihara dan meningkatkan kedisiplinan yang baik merupakan hal yang cukup sulit karena banyak faktor yang mempengaruhinya.Terkadang kekurangtahuan karyawan tentang peraturan, prosedur, dan kebijakan yang ada merupakan penyebab terbanyak tindakan indisipliner.

\section{Kinerja Karyawan}

Kinerja pada dasarnya bisa diartikan sebagai sebuah kesuksesan seseorang dalam melakukan suatu pekerjaan, kinerja yang baik adalah kinerja yang mengikuti tata cara atau prosedur sesuai standar yang telah ditetapkan. Menurut Sedarmayanti (2010:176), kinerja 
merupakan hasil kerja seseorang, dimana keseluruhan hasil tersebut dapat dibuktikan secara nyata dan dapat diukur.

Kinerja bisa dinilai dan diukur secara objektif bisa meningkatkan motivasi karyawan untuk bisa bekerja dengan lebih baik, tetapi jika kinerja dinilai secara subjektif dan tidak adanya pengukuran secara jelas akan menimbulkan karyawan terdemotivasi dan terjadi ketidakpuasan dalam bekerja (Sinambela, 2016:519).

Menurut Mangkunegara (2013:67), faktor-faktor yang dapat mempengaruhi kinerja karyawan dalam melakukan tugasnnya dapat bersumber dari dua faktor yaitu faktor individu dan faktor lingkungan dalam sebuah organisasi. Perusahaan bisa meningkatkan kinerja karyawaanya apabila di dalam diri karyawannya memiliki kesadaran untuk bisa patuh dan mentaati semua aturan yang ada di perusahaan. Faktor lingkungan organisasi juga bisa mempengaruhi sebuah kinerja karyawan, lingkungan kerja yang baik akan dapat mempermudah seorang karyawan dalam menjalankan pekerjaannya karena seorang karyawan akan merasa terbantu dengan lingkungan kerja fisiknya dan akan merasa lebih nyaman bekerja dengan lingkungan non fisiknya, dengan memperhatikan disiplin kerja dan lingkungan kerja seorang karyawan akan memiliki kinerja yang sangat baik sehingga tujuan perusahaan bisa tercapai.

Menurut Mangkunegara (2013:67), kinerja karyawan merupakan sebuah hasil kerja secara kualitas dan kuantitas yang bisa dicapai oleh seorang karyawan dalam melakukan tugasnya sesuai dengan tanggung jawab yang telah diberikan kepadanya. Kinerja karyawan adalah merupakan keadaan atau semangat yang dimiliki oleh karyawan dalam setiap mengerjakan pekerjaannya. Menurut Rivai (2004:309), kinerja karyawan merupakan perilaku yang nyata kurang diperlihatkan setiap orang sebagai prestasi kerja yang dihasilkan oleh karyawan sesuai dengan perannya dalam perusahaan.

Dimensi dari kinerja karyawan tersendiri yaitu: 1) Kualitas hasil kerja 2) Kuantitas Hasil Kerja 3) Ketepatan waktu 4) Kemampuan bekerja (Damayanti et al., 2018)

Berdasarkan latar belakang masalah dan dukungan landasan teoritis yang dikemukakan, maka penulis merumuskan suatu hipotesa sebagai berikut: "Diduga Disiplin Kerja Berpengaruh Signifikan Terhadap Kinerja Karyawan pada Bank OCBC NISP cabang cibadak”

\section{PENGEMBANGAN HIPOTESIS}

Menurut Rofi (2012), disiplin kerja karyawan adalah faktor yang paling dominan sehingga disiplin kerja perlu ditingkatkan supaya semu harapan karyawan bisa tercapai dan mendapatkan sebuah kepuasan dalam bekerja. Hal ini dapat meningkatkan kinerja karyawan tersebut. Perusahaan harus memberikan sanksi bagi karyawan yang melanggar aturan dan melakukan pengawasan yang lebih ketat untuk meningkatkan kinerja karyawan (Dwipayana, 2014).

Sanksi yang diberikan harus tepat sehingga karyawan yang melanggar aturan dan tata tertib perusahaan agar tidak melakukan kesalahan yang sama (Krisnanda \& Sudibya, 2014). Berdasarkan penelitian sebelumnya mengenai disiplin kerja dan kinerja karyawan dapat disimpulakan bahwa Hipotesis ialah dugaan sementara masalah yang ada dalam penelitian. Dalam penelitian penulis menduga ada pengaruh positif Disiplin kerja terhadap Kinerja Karyawan.

Dalam penelitian ini Disiplin kerja sebagai X (variable bebas) yang merupakan kemampuan individu untuk mematuhi peraturan dan norma yang ada diperusahaan. Sedangkan Kinerja Karyawan sebagai Y (Variabel terikat) yang merupakan tanggung jawab serta hasil kerja karyawan yang sesuai dengan kualitas dan kuantitas serta ketetapan perusahaan. Penulis mendua adanya pengaruh positif Disiplin kerja (X) terhadap Kinerja Karyawan (Y).

H1: Pengaruh Disiplin kerja terhadap Kinerja Karyawan 
Berdasarkan Hipotesis diatas model penelitian dapat digambarkan sebagai berikut:

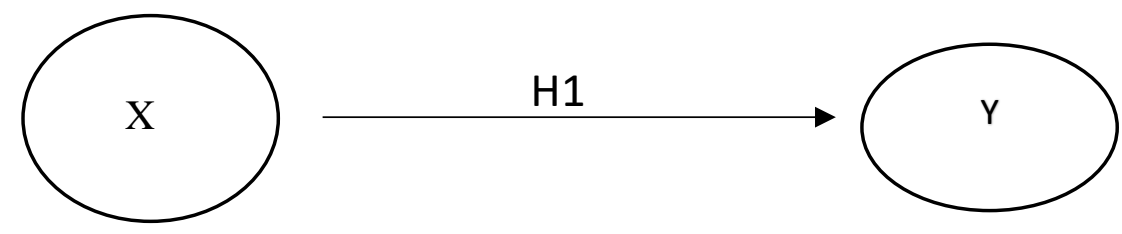

Gambar 1 Paragdigma Penelitian

\section{METODE PENELITIAN}

Dalam penelitian ini menggunakan Teknik pengumpulan data kuisioner dengan melakukan dan memberikan daftar pertanyaan pada responden dengan poulasinya yaitu karyawan pada Bank OCBC NISP cabang Cibadak. Untuk mengolah data dari hasil penelitian terrsebut maka peneliti mengunakan Teknik analisi data menggunakan metode Regresi Linier sederhana. Sedangkan untuk menguji hipotesis dengan uji hipotesis secara parsial (uji t) dan uji hipotesis yaitu secara simultan (uji F)

\section{HASIL DAN PEMBAHASAN}

Regresi Linear Sederhana yang untuk mengetahui bagaimana dan pengaruh apakah pada variabel Disiplin Kerja (X) berpengaruh terhadap variabel Kinerja Karyawan (Y) yang menggunakan analisis regresi linear sederhana. Hasil pengolahan data dari Regresi Linear Sederhana dengan menggunakan SPSS versi 23.00 dan dapat dilihat pada hasilnya sebagai berikut:

Adapun hasil yang diperoleh oleh peneliti setelah melakukan penyebaran kuesioner melalui google from adalah sebagai berikut:

Tabel 1. Hasil Uji Validitas X dan Y

\begin{tabular}{lllll}
\hline Variabel & Rhitung & Rtabel & Sig. & Hasil \\
\hline X1 & 0,832 & 0,361 & 0.000 & Valid \\
X2 & 0,701 & 0,361 & 0.000 & Valid \\
X3 & 0,775 & 0,361 & 0.000 & Valid \\
X4 & 0,901 & 0,361 & 0.000 & Valid \\
X5 & 0,758 & 0,361 & 0.000 & Valid \\
Y1 & 0,730 & 0,361 & 0.000 & Valid \\
Y2 & 0,843 & 0,361 & 0.000 & Valid \\
Y3 & 0,777 & 0,361 & 0.000 & Valid \\
Y4 & 0,722 & 0,361 & 0.000 & Valid \\
Y5 & 0,702 & 0,361 & 0.000 & Valid \\
Y6 & 0,650 & 0,361 & 0.000 & Valid \\
Y7 & 0,602 & 0,361 & 0,001 & Valid \\
Y8 & 0,472 & 0,361 & 0,013 & Valid \\
\hline
\end{tabular}

Sumber: Diolah peneliti, 2019

Tabel 2. Hasil Uji Reliabilitas Y Dan X

\begin{tabular}{lclc}
\hline \multicolumn{3}{l}{ Reliability Statistic Y } & \multicolumn{2}{l}{ Reliability Statistic $\mathbf{X}$} \\
\hline $\begin{array}{l}\text { Cronbach's } \\
\text { Alpha }\end{array}$ & N of items & $\begin{array}{l}\text { Cronbach's } \\
\text { Alpha }\end{array}$ & N of item \\
0,839 & 8 & 0,856 & 5 \\
\hline
\end{tabular}

Sumber : Diolah peneliti,2019 
Reliabilitas variabel $\mathrm{Y}$ adalah 0,839 dan reliabilitas variabel $\mathrm{X}$ adalah 0,856 skor diatas $\mathrm{r}$ Kritis 0,3 maka akan dikatakan reliabel sehingga dapat mengukur analisis data.

Tabel 3. Analisis Regresi Linear

Coefficients $^{\mathrm{a}}$

\begin{tabular}{|c|c|c|c|c|c|c|}
\hline \multirow[b]{2}{*}{ Model } & & \multicolumn{2}{|c|}{ Unstandardized Coefficients } & \multicolumn{3}{|l|}{$\begin{array}{l}\text { Standardized } \\
\text { Coefficients }\end{array}$} \\
\hline & & B & Std. Error & Beta & $\mathbf{t}$ & Sig. \\
\hline \multirow[t]{2}{*}{1} & (Constant) & 4,269 & 4,216 & & 1,012 & ,321 \\
\hline & $\mathbf{X}$ & 1,146 & 167 & 808 & 6,855 &, 000 \\
\hline
\end{tabular}

Sumber: Diolah peneliti, 2019

Tabel diatas menjelaskan bahwa nilai konstansta sebesar 4,269 sedangkan nilai variabel X (Disiplin Kerja) 1,146 sehingga persamaan ditulis sebagai berikut:

$$
\begin{aligned}
& \mathrm{Y}=\mathrm{a}+\mathrm{bX}+\mathrm{e} \\
& \mathrm{Y}=4,269+1,146+\varepsilon
\end{aligned}
$$

1. Persamaan diatas menjelaskan konstanta sebesar 4,269 yang berarti nilai konsisten variabel Y sebesar 4,269.

2. Koefisien regresi $\mathrm{X}$ sebesar 1,146 menyatakan bahwa setiap penambahan $1 \%$ nilai $\mathrm{x}$. maka nilai partisipasi bertambah 1,146 . Koefisien regresi bernilai positif. dikatakan bahwa disiplin kerja terhadap kinerja karyawan adalah berpengaruh positif

\section{Tabel 4. Koefisien Korelasi}

\begin{tabular}{lllll}
\multicolumn{2}{l}{ Model Summary } & & $\begin{array}{l}\text { Adjusted } \\
\text { Square }\end{array}$ & $\begin{array}{c}\text { R Std. Error of } \\
\text { the Estimate }\end{array}$ \\
\hline $1 \quad$ Rodel & R & R Square & Sq & \\
\hline a. Predictors: (Constant), X & & \\
\hline
\end{tabular}

Sumber: Diolah peneliti, 2019

Berdasarkan tabel diatas dijelaskan bahwa besarnya nilai korelasi ( $R$ ) yang tinggi yaitu sebesar 0,808 dan diperoleh koefisien determinasi ( $\mathrm{R}$ Square ) sebesar 0,653 yang berarti bahwa variabel disiplin kerja ( $\mathrm{x}$ ) terhadap Kinerja Karyawan ( y) adalah sebesar 65,3 \%

\section{Tabel 5. Hasil Uji F}

\begin{tabular}{lllllll}
\hline \multicolumn{2}{l}{ ANOVA $^{\text {a }}$} & \multicolumn{7}{l}{} \\
\hline Model & & Sum of Squares & df & Mean Square & F & Sig. \\
\hline $\mathbf{1}$ & Regression & 324,380 & 1 & 324,380 & 46,989 &, $000^{\text {b }}$ \\
& $\begin{array}{l}\text { Residual } \\
\text { Total }\end{array}$ & 172,582 & 25 & 6,903 & & \\
& 496,963 & 26 & & & \\
a. Dependent Variable: Y & & & & \\
b. Predictors: (Constant), X & & & & \\
\hline
\end{tabular}

Sumber: Diolah peneliti, 2019

Tabel ditas menjelaskan bahwa nilai Fhitung $=46,989$ dan nilai regresi memiliki tingkat signifikan $0.000<0.05$. Maka dapat disimpulkan bahwa adanya pengaruh yang positif dan signifikan antara variabel disiplin kerja ( $\mathrm{x}$ ) terhadap variabel Kinerja Karyawan ( y ) diterima 
Tabel 6. Hasil Uji T

\begin{tabular}{|c|c|c|c|c|c|c|}
\hline \multicolumn{6}{|c|}{ Coefficients $^{\mathrm{a}}$} & \multirow[b]{3}{*}{ Sig. } \\
\hline \multirow[b]{2}{*}{ Model } & & \multicolumn{2}{|c|}{ Unstandardized Coefficients } & \multicolumn{2}{|c|}{$\begin{array}{l}\text { Standardized } \\
\text { Coefficients }\end{array}$} & \\
\hline & & B & Std. Error & Beta & $\mathbf{t}$ & \\
\hline 1 & (Constant) & 4,269 & 4,216 & & 1,012 & 321 \\
\hline & $\mathbf{X}$ & 1,146 &, 167 & 808 & 6,855 &, 000 \\
\hline
\end{tabular}

Sumber: Diolah peneliti, 2019

Tabel diatas menjelaskan bahwa nilai signifikan sebesar $0.000<0.05$. Maka dapat disimpulkan adanya pengaruh positif dan signifikan antara disiplin kerja (x) dengan Kinerja Karyawan (y). Sedangkan nilai Thitung dan Ttabel yaitu 6,855 <2,042272456. Maka dapat diartikan adanya pengaruh positif dan signifikan antara disiplin kerja dalam meningkatkan kinerja karyawan Bank OCBC NISP Cabang Cibadak

\section{PEMBAHASAN}

Disiplin kerja secara parsial berpengaruh signifikan positif terhadap kinerja karyawan, artinya pengaruh disiplin kerja terhadap kinerja karyawan searah, apabila disiplin kerja meningkat maka kinerja karyawan juga akan meningkat namun apabila disiplin kerja karyawan menurun maka kinerja karyawan juga ikut menurun. Jawaban responden pada variabel disiplin kerja menunjukan bahwa item pertama yaitu karyawan berusaha tidak melanggar peraturan yang berlaku ditempat kerja merupakan item yang paling mendominasi atau paling mempengaruhi kinerja karyawan.

Hal itu menunjukan bahwa karyawan memiliki kesadaran untuk taat dan patuh terhadap peraturan yang berlaku ditempat kerja, kepatuhan terhadap peraturan kerja salah satunya bisa dengan karyawan taat dengan peraturan jam kerja sehingga berangkat sebelum masuk kerja, pulang kerja pada waktunya, bekerja sesuai jam waktu kerja, menggunakan waktu istirahat sesuai dengan ketentuan dan tidak melanggar peraturan. Ketaatan pada peraturan akan membuat kenyaman dan kelancaran karyawan dalam bekerja.

Selain itu indikator yang paling dominan dalam variabel disiplin kerja adalah ketaatan pada peraturan kerja, karyawan yang patuh terhadap peraturan akan memahami peraturan yang berlaku dan memahami konsekuensi apabila melakukan tindakan indisipliner yang membuat mereka berperilaku disiplin dalam bekerja sehingga kinerja karyawan akan meningkat.

Karyawan yang patuh terhadap peraturan akan memahami peraturan yang berlaku dan memahami konsekuensi apabila melakukan tindakan indisipliner yang membuat mereka berperilaku disiplin dalam bekerja sehingga kinerja karyawan akan meningkat

Dan dari hasil pembahasan yang telah dilakukan peneliti diatas, telah didapatkan hasil analisis bahwa Disiplin kerja berpengaruh positif dan segnifikan terhadap knerja karyawa pada BANK OCBC NISP cabang cibadak. Hal tersebut dapat di buktikan setelah pengujian secara parsial (uji t). Terdapat berbagai macam jenis faktor yang mendukung dalam meningkatkan kinerja karyawan yang salah satunya yaitu meningkatkan semangat keraja para karyawan, kemudian memberi porsi pekerjaan yang sesuai, memberikan waktu pekerjaan yang tepat, dan lain-lain.

Dalam pelaksanaan disiplin kerja manajemen dapat membagi bentuk-bentuk kedisiplinan dalam bekerja tersebut dalam dua macam, yang mana diutarakan oleh Mangkunegara (2009: 281) sebagai berikut: (1) disiplin yang preventif yaitu dimana disiplin yang berupaya untuk menggerakkan karyawan nya untuk mengikuti dan mematuhi segala pedoman kerja, peraturan berlaku yang telah digariskan oleh perusahaan (2) disiplin korektif yaitu kedisiplinan yang diberikan kepada karyawan yang melanggar dengan sanksi yang berlaku. 
Hasil penelitian yang dilakukan dalam penelitian ini maupun penelitian sebelumnya dapat disimpulkan bahwa benar disiplin kerja memiliki pengaruh terhadap kinerja karyawan. Semakin tinggi disiplin kerja maka semakin tinggi kinerja yang dihasilkan karyawan. Sesuai dengan pendapat Sinambela (2016:332) yang menyatakan bahwa terdapat hubungan yang signifikan di antara variabel kinerja dengan disiplin kerja. Apabila ditelaah sebenarnya disiplin kerjalah yang mempengaruhi kinerja karyawan, artinya semakin tinggi disiplin kerja seseorang maka akan semakin tinggi juga kinerja orang tersebut.

Maka dari itu disiplin kerja berpengaruh positif tehadap kinerja karyawan pada Bank OCBC NISP cabang cibadak diterima dan teruji kebenarannya.

\section{PENUTUP}

\section{Kesimpulan}

Berdasarkan analisis yang dilakukan peneliti menemukan beberapa kesimpulan untuk menjawab pertanyaan pada penelitian ini. Dengan teknik analisis regresi sederhana diketahui bahwa total pengaruh variabel $\mathrm{X}$ terhadap variabel $\mathrm{Y}$ adalah sebesar 0,653 atau 65,3\% dan epsilon atau sisa pengaruh independent lainnya yang berpengaruh terhadap kinerja karyawan ( Y ) namun tidak diteliti adalah sebesar 0,347 atau 34,7\%. Selanjutnya setelah dilakukan hipotesis secara parsial dan simultan didapatkan hasil penelitian yang menunjukan bahwa terdapat pengaruh yang positif dan signifikan secara simultan antara variabel $\mathrm{X}$ terhadap $\mathrm{Y}$.

Disiplin kerja berpengaruh terhadap kinerja karyawan. Hal ini mendukung penelitian yang dilakukan Rofi (2012) yang menyatakan bahwa disiplin kerja merupakan faktor yang paling dominan dalam mempengaruhi kinerja karyawan. Oleh karena itu, disiplin kerja perlu ditingkatkan agar harapan karyawan dapat tercapai, karyawan mendapatkan kepuasan dalam bekerja dan karyawan dapat meningkatkan kinerja karyawan.

Lingkungan kerja dan disiplin kerja berpengaruh signifikan terhadap kinerja karyawan. Penelitian ini mendukung hasil penelitian terdahulu yang dilakukan oleh Pramana dan Sudharma (2013) yang mengatakan bahwa lingkungan kerja yang nyaman dapat membuat karyawan bersemangat dalam bekerja. Hal ini menunjukkan bahwa karyawan tersebut memiliki tanggung jawab yang besar, sehingga kinerja karyawan meningkat.

\section{Saran}

Untuk penelitian yang selanjutnya, disarankan untuk menggunakan subvariabel lain agar dapat dijadikan sebagai alat ukur variabel kinerja karyawan dan memilih data lain sebagai referensi penelitian agar hasil peneliti lebih maksimal serta memiliki responden yang cukup utnuk sebagai dasar pengolahan data agar valid.

\section{DAFTAR PUSTAKA}

Damayanti, R., Hanafi, A., \& Cahyadi, A. (2018). Pengaruh Kepuasan Kerja Terhadap Kinerja Karyawan (Studi Kasus Karyawan Non Medis Rs Islam Siti Khadijah Palembang). Jurnal Ilmiah Manajemen Bisnis Dan Terapan, 2, 75-86.

Dwipayana, M. A. (2014). Pengaruh disiplin kerja, motivasi dan gaya kepemimpinan terhadap kinerja karyawan pada percetakan Sadha Jaya di Denpasar. E-Jurnal Manajemen Universitas Udayana, 3(1), 225-242.

Harlie, M. 2010. Pengaruh Disiplin Kerja, Motivasi dan Pengembangan Karier Terhadap Kinerja Pegawai Negeri Sipil Pada Pemerintah Kabupaten Tabalong di Tanjung Kalimantan Selatan. Jurnal Manajemen dan Akuntansi 11 (2): 10-23.

Hasibuan, H. Malayu. 2006. Manajemen Sumber Daya Manusia Ed. Revisi. :Jakarta: Bumi Aksar 
Krisnanda, N. A., \& Sudibya, G. A. (2014). Pengaruh disiplin kerja, motivasi kerja dan kompensasi terhadap kinerja karyawan Respati Sanur Beach Hotel. E-Jurnal Manajemen Universitas Udayana, 3(7).

Mangkunegara, Anwar P. 2013. Manajemen Sumber Daya Manusia Perusahaan. Bandung: PT. Remaja Rodaskarya Offset.

Pramana, A. G. K., \& Sudharma, I. N. (2013). Pengaruh kompensasi, lingkungan kerja fisik dan disiplin kerja terhadap kinerja karyawan. E-Jurnal Manajemen Universitas Udayana, 2(9).

Rivai, V. (2004). Manajemen sumber daya manusia untuk perusahaan: dari teori ke praktik. PT RajaGrafindo Persada.

Sedarmayanti. 2009. Sumber Daya Manusia dan Produktivitas Kerja. Bandung: Mandar Maju. Sinambela, Lijan. 2016. Manajemen Sumber Daya Manusia. Jakarta: Bumi Aksara.

Rofi, A. (2012). Pengaruh disiplin kerja dan pengalaman kerja terhadap prestasi kerja karyawan pada departemen produksi PT Leo Agung Raya Semarang. Jurnal Ilmu Manajemen dan Akun- tansi Terapan, 3(1), 1-21. 